\title{
An Investigation of Synthesized Samarium Oxychloride in Molten LiCl-KCl
}

\author{
Vickram Singh ${ }^{\mathrm{a}}$, Christopher Bruneau ${ }^{\mathrm{a}}$, Zachary Karmiol $^{\mathrm{a}}$, Dev Chidambaram ${ }^{\mathrm{a}, \mathrm{b}, *}$

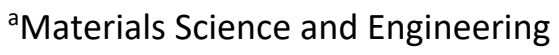

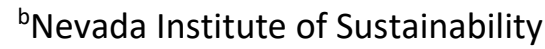 \\ University of Nevada, Reno. Reno, NV 89557-0388 \\ *dcc@unr.edu
}

\begin{abstract}
The spectroscopic and electrochemical properties of synthesized samarium oxychloride were investigated as they relate to the pyrochemical reprocessing of used nuclear fuel in the molten $\mathrm{LiCl}-\mathrm{KCl}$ eutectic. A qualitative, in situ investigation of oxychloride formation was conducted using electroanalytical voltammetry and Raman spectroscopy. Electroanalytical properties of samarium in trivalent chloride and oxychloride form were investigated using cyclic voltammetry. Electrochemical relationships developed for aqueous systems, and their applicability to the reaction couples of interests, were evaluated using the Randles-Sevcik equation. The diffusion behavior of chloride and oxychloride samarium is discussed in terms of electrochemical current response. Synthesized oxychloride was also analyzed using various solidstate characterization techniques to better understand its chemical properties. The nature of oxychloride formation, solvation in the molten eutectic, implications in electrochemical processing, and the management of nuclear material in high-temperature systems are discussed.
\end{abstract}

Keywords: SmOCI, XRD, TEM, and Raman spectroscopy. 


\section{Introduction}

As the international community transitions to more sustainable and environmentally-friendly energy sources, nuclear power remains one of the cleanest sources of electricity in terms of greenhouse gas (GHG) emissions. The International Atomic Energy Agency's (IAEA) Climate Change and Nuclear Power 2018 report projects nuclear energy's role in electricity markets to grow anywhere from $24-184 \%$ in terms of generating capacity by $2050 .{ }^{1}$ Technological improvements in power plant design, passive safety features, proliferation-resistant fuel cycles, and analytical nuclear material management methodology will allow for nuclear energy to penetrate emerging electricity markets. ${ }^{2}$ Nuclear power plants are considered to be in their third technological generation as of 2019, with a Generation-III+ fleet of reactors currently being commercialized. Generation-IV nuclear power plants and fuel cycles drift away from aqueous systems in favor of higher-temperature materials, such as molten salts. Securing nuclear material and optimizing process conditions for economically viable power and fuel production remain the main obstacles to advanced system commercialization. ${ }^{3}$

Molten chloride salts are candidate materials for nuclear power plant cooling, fueled-salt power reactors, and the electrochemical processing of nuclear material. Used nuclear fuel (UNF) is not reprocessed internationally on a large scale; however, a few nations recycle UNF using a process termed PUREX (Plutonium Uranium Redox Extraction). PUREX relies on aqueous media to separate, pure uranium and plutonium streams that exhibit dangerously high enrichment levels. PUREX is riddled with problems associated with radiolysis and criticality that manifest in the form of waste management and proliferation concerns. ${ }^{4,5}$ The pyrochemical reprocessing of UNF employs the molten $\mathrm{LiCl}-\mathrm{KCl}$ eutectic salt at $500{ }^{\circ} \mathrm{C}$ to electrochemically deposit uranium, plutonium, and transuranic (TRU) chlorides in metallic form on a combination of solid and liquid metal electrodes. ${ }^{5,6}$ The impure and high temperature nature of plutonium streams in the pyrochemical flowsheet create a more proliferation-resistant process. ${ }^{7}$ Although the fuel is refined and consolidated in metallic form, electrolytic reduction unit operations can incorporate existing 
light water reactor (LWR) oxide fuel into a closed nuclear fuel cycle employing the pyrochemical process. ${ }^{6}$ Electroanalytical and spectroscopic investigations of actinide and lanthanide chloride analytes in the molten $\mathrm{LiCl}-\mathrm{KCl}$ eutectic produce information regarding analyte chemistry, electrochemical separation efficiency, and process scale-up..$^{8-15}$ The proposed process flowsheet for the pyrochemical reprocessing of UNF, reported by Williamson et al., is shown in Figure $1 .^{6}$

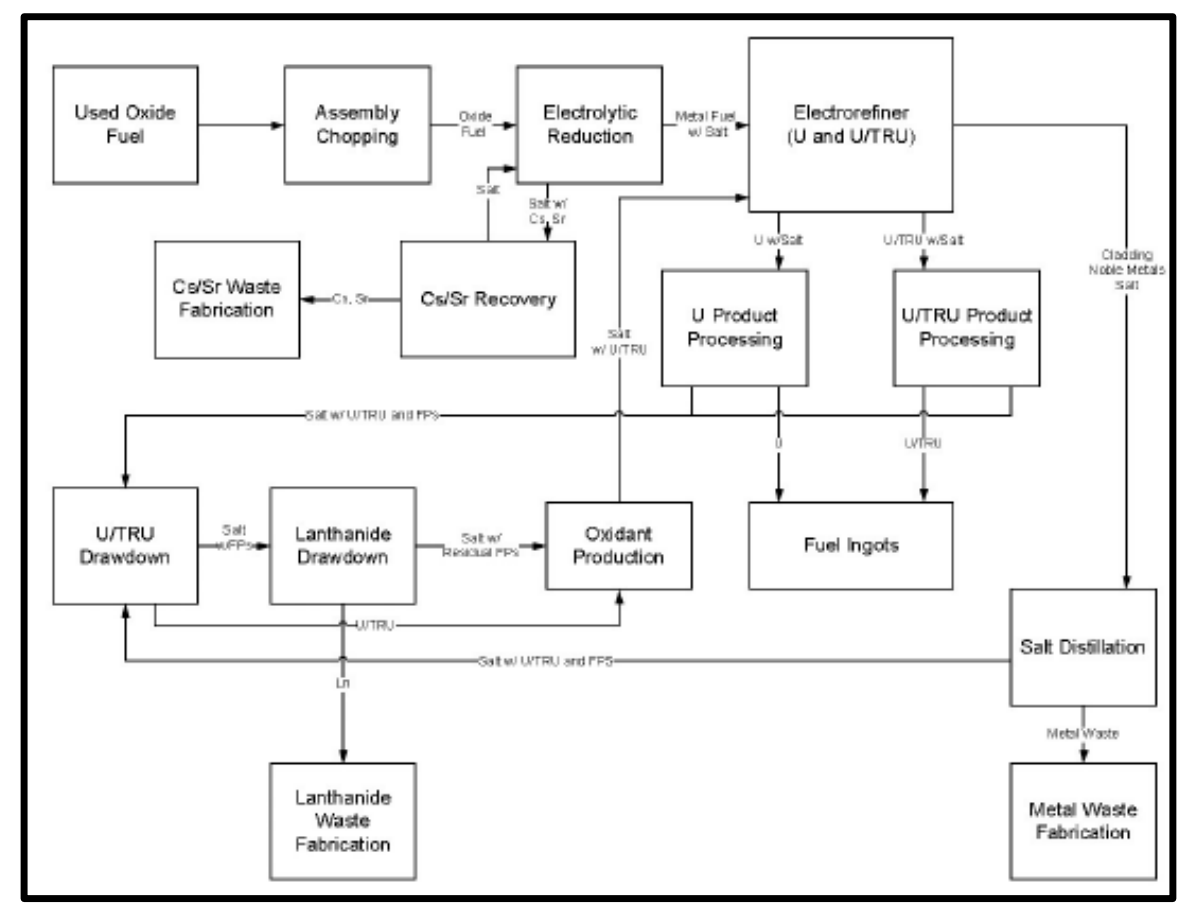

Figure 1: Proposed pyroprocessing flowsheet published by Williamson et al. ${ }^{6}$ reports a variety of unit processes (electrorefiner, oxidant production, lanthanide drawdown, U/TRU drawdown) that require concrete understanding of analyte behavior before optimization can be pursued. Figure used with permission from Dr. Williamson.

Oxychloride chemistry plays an important role when addressing lanthanide and actinide chemistry in molten chloride salts. Oxychloride formation, predominantly in the form of precipitates, can have negative effects on process efficiency along with creating nuclear material management concerns regarding hold up and material loss. Oxychloride precipitation has also been proposed as a method for co-precipitation and consolidation of nuclear material in molten salt. ${ }^{16,17}$ Furthermore, also oxychloride formation presents a potential for nuclear material buildup due to moisture or impurities in alternative electrochemical processes related to the nuclear industry, specifically the conversion of plutonium pits in 
high-temperature molten salt. ${ }^{18}$ The literature data regarding oxychloride formation in the $\mathrm{LiCl}-\mathrm{KCl}$ molten eutectic is limited and requires further investigation to fully understand solvation mechanisms, effects on electroanalytical measurements, and characterization of relevant reaction products. ${ }^{16,17,19}$

This paper presents a synthesis method for, and characterization of, samarium oxychloride $(\mathrm{SmOCl})$ in the molten $\mathrm{LiCl}-\mathrm{KCl}$ eutectic at $500{ }^{\circ} \mathrm{C}$. Additionally, solid state characterization is reported to confirm the synthesis of $\mathrm{SmOCl}$ before the in situ analysis of the analyte using electroanalytic measurements and polarized Raman spectroscopy. Cyclic voltammetry (CV) results are reported and discussed in terms of current response and empirical relationships applicability. CV and in situ Raman also provide a qualitative evaluation of oxychloride formation in the molten $\mathrm{LiCl}-\mathrm{KCl}$ eutectic. The results are discussed in term of engineering implications related to nuclear material management in hightemperature molten salt systems.

\section{Experimental}

\section{$\underline{\text { General features }}$}

All molten salt studies were conducted in ultra-high purity argon atmosphere (Airgas 99.99\%) inside an inert glovebox maintained under $1 \mathrm{ppm}$ moisture and oxygen content. The electroanalytical and in situ Raman spectroscopy setup has been previously presented by the authors for low concentration lanthanide studies in the same eutectic system..$^{20-23}$ The experimental apparatus employed for both spectroscopic and electroanalytical molten salt investigations is shown in Figure 2. 


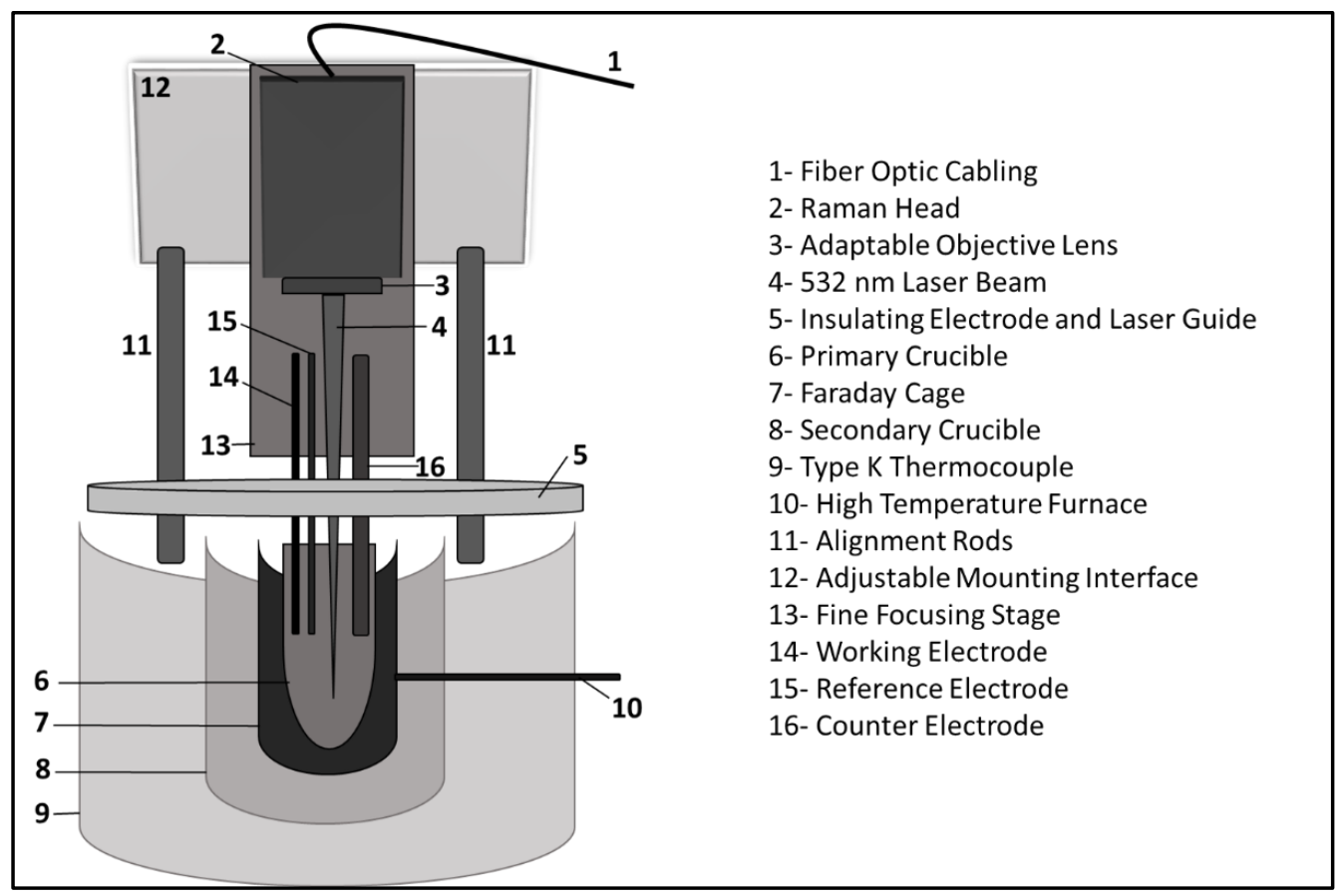

Figure 2: Experimental setup employed for spectroscopic and electroanalytical investigations in molten LiCl-KCl eutectic consists of precision alignment stages for electrochemical and spectroscopic focusing, electrode alignment mounts, fiber cabling for 532 $\mathrm{nm}$ laser excitation, a polarized Raman probe, and a high-temperature ceramic cylindrical furnace.

Uncertainties associated with thermal gradients were mitigated with an insulating ceramic furnace cap fabricated with electrode alignment holes and a laser beam path for Raman analysis. Alumina tubes were installed to ensure electrode alignment is repeatable and precise. Molten salt samples were contained in $55 \mathrm{~mL}$ alumina crucibles nested inside stainless-steel Faraday cages that remove electrical current noise produced by the furnace heaters. The system was equipped with a three-electrode electrochemical stage and Raman probe with polarization capability. A $532 \mathrm{~nm}$ wavelength laser was utilized for Raman excitation. A K-type thermocouple was installed to provide feedback to the furnace controller with $\pm 2{ }^{\circ} \mathrm{C}$ temperature precision. Electrode positioning and Raman probe focusing were controlled by a highresolution translation stage with a LabVIEW National Instruments software user interface to ensure accurate and repeatable placement of electrodes inside the molten salt matrix and to ensure the laser excitation converges in the solution to excite the bonds associated with dissolved analyte complexes rather than electrodes or crucible walls. 


\section{Cyclic Voltammetry Methods}

$\mathrm{CV}$ is a three-electrode electrochemical method that relies on a cyclic potential sweep to scan a voltage range for analyte-specific redox reactions. Current response can be correlated to analyte concentration if the diffusion behavior of the analyte is well understood. ${ }^{24}$ The Randles-Sevcik equation can be applied to CV data assuming all diffusion is mass transfer limited, linear in nature, and the redox reaction of interest is reversible. ${ }^{24}$ The Randles-Sevcik relationship is reported in Equation 1. Once diffusion coefficient values are established, current response has the potential to be correlated to concentration for process monitoring and nuclear security applications. ${ }^{25}$

$i_{p}=0.4463 \cdot n \cdot F \cdot A \cdot C_{i} \cdot\left(\frac{n \cdot F}{R \cdot T}\right)^{1 / 2} \cdot v^{1 / 2} \cdot D^{1 / 2}$

Here $i_{p}$ is the peak current response, $n$ is the number of electrons transferred during the redox reaction, $F$ is Faraday's constant, $A$ is the surface area of the working electrode (WE), $C_{i}$ is the bulk concentration of the dissolved analyte of interest, $R$ is the ideal gas constant, $T$ is temperature, $v$ is the potential scan rate, and $D$ is the diffusion coefficient of the analyte of interest. ${ }^{24}$ The working electrode (WE) and counter electrode (CE) consisted of a $1 / 16^{\prime \prime}$ and $1 / 8^{\prime \prime}$ diameter tungsten rod, respectively. A $5 \mathrm{~mol} \% \mathrm{Ag} \mid \mathrm{AgCl}$ reference couple encased in Pyrex which has been previously deployed for voltammetry experiments in the same eutectic was employed as a reference electrode. ${ }^{10}$ The peak current versus square-root of scan rate relationship was studied for both $\mathrm{SmCl}_{3}$ and $\mathrm{SmOCl}$. Peak currents were measured five times at each of the following scan rates for each CV analysis: $100 \mathrm{mV} / \mathrm{s}, 150 \mathrm{mV} / \mathrm{s}, 200 \mathrm{mV} / \mathrm{s}, 250 \mathrm{mV} / \mathrm{s}$, and $300 \mathrm{mV} / \mathrm{s}$.

\section{Samarium oxychloride synthesis}

$\mathrm{LiCl}-\mathrm{KCl}$ melts were prepared by mixing LiCl (Alfa Aesar 99\% pure) and $\mathrm{KCl}$ (Alfa Aesar 99\% pure) at 46 wt.\% and 54 wt.\%, respectively. ${ }^{26}$ Precursor salts utilized to prepare the final eutectic were first baked under vacuum at $200{ }^{\circ} \mathrm{C}$ in order to minimize moisture-induced impurities. Anhydrous $\mathrm{SmCl}_{3}$ (Alfa Aesar, $99.9 \%$ pure) was dissolved directly into the molten $\mathrm{LiCl}-\mathrm{KCl}$ eutectic at $500{ }^{\circ} \mathrm{C}$ and agitated for eight 
hours. Synthesis of $\mathrm{SmOCl}$ was accomplished through the dissolution of $\mathrm{O}^{2-}$ ions in the eutectic with the addition $\mathrm{Li}_{2} \mathrm{CO}_{3}$ to the $\mathrm{SmCl}_{3}-\mathrm{LiCl}-\mathrm{KCl}$ solutions. The reaction mechanism for $\mathrm{SmOCl}$ formation and precipitation in this manner has been reported in the literature by Castrillejo et al. ${ }^{19,27}$ The dissolution of $\mathrm{SmCl}_{3}, \mathrm{Li}_{2} \mathrm{CO}_{3}$, and formation of $\mathrm{SmOCl}$ are reported in Equations 2, 3, and 4, respectively.

$\mathrm{SmCl}_{3}(s) \leftrightarrow \mathrm{Sm}^{3+}+3 \mathrm{Cl}^{-}$

$\mathrm{Li}_{2} \mathrm{CO}_{3}(\mathrm{~s}) \leftrightarrow 2 \mathrm{Li}^{+}+\mathrm{O}^{2-}+\mathrm{CO}_{2}(\mathrm{~g})$

$\mathrm{Sm}^{3+}+\mathrm{O}^{2-}+\mathrm{Cl}^{-} \leftrightarrow \operatorname{SmOCl}(s)$

After addition of $\mathrm{Li}_{2} \mathrm{CO}_{3}$, melts were agitated until $\mathrm{CO}_{2}$ gas bubbling halted, indicating the reaction had completed.

$\mathrm{SmCl}_{3}$ was solvated in $\mathrm{LiCl}-\mathrm{KCl}$ at a concentration of $3.3 \times 10^{-4} \mathrm{~mol} \mathrm{~cm}^{-3}$, and $\mathrm{Li}_{2} \mathrm{CO}_{3}$ was added to the solution in an equimolar quantity. Upon completion of the synthesis reaction, the melt was allowed to solidify. Carboxylic acid groups on ethylenediaminetetraacetic acid (EDTA) were deprotonated in DI $\mathrm{H}_{2} \mathrm{O}$ in solution through the addition of $\mathrm{NaOH}$. The deprotonated solution was used to rinse off remaining eutectic and pull any unreacted $\mathrm{SmCl}_{3}$ into solution as well. The EDTA forms a 1:1 complex with the unreacted $\mathrm{SmCl}_{3}$, leaving only the $\mathrm{SmOCl}$ precipitate behind. Excess EDTA was present to ensure all unreacted $\mathrm{SmCl}_{3}$ was fully chelated. The remaining solution containing the synthesized precipitate was then centrifuged so that precipitate powder could be consolidated. The powder was then allowed to dry before undergoing solid state characterization.

Synthesis is complete once $\mathrm{CO}_{2}$ bubbling is no longer observed. $\mathrm{Li}_{2} \mathrm{CO}_{3}$ is added in small increments while the melt is agitated to ensure the salt mixture does not overflow out of the containment crucible due to $\mathrm{CO}_{2}$ bubbling. Once bubbling has halted, the melt is agitated for an extended period of time to ensure the reaction proceeds to completion. After agitation, the melt is observed to be transparent with a suspension of white precipitate, assumed to be $\mathrm{SmOCl}$. After reaction completion, the melt is cooled and dissolved in the EDTA complex for separation and consolidation. 


\section{$\underline{\text { Solid state characterization }}$}

Synthesized precipitate was analyzed using a variety of solid-state characterization methods to confirm the formation of SmOCl. X-ray diffraction (XRD) patterns were obtained from the collected precipitates using a Rigaku Smartlab X-ray diffractometer. Diffraction patterns were analyzed using a PDXL software package. A Hitachi S-4700 field emission scanning electron microscope (SEM) equipped with energy dispersive $x$-ray spectroscopy (EDS) was employed to investigate precipitate morphology and elemental makeup, respectively. Transmission electron microscopy (TEM) analysis was carried out using a JEOL-JEM 2100F Analytical TEM. A Thermo Scientific DXR Raman microscope equipped with a $10 \mathrm{~mW}$, $532 \mathrm{~nm}$ wavelength laser was employed for solid-state Raman analysis of the precipitate.

\section{Results and Discussion}

\section{Synthesis and Solid-State Characterization}

The precipitate remains a white color throughout the separation and consolidation operations. Once dry, solid-state characterization is commenced to confirm the presence of SmOCl. The XRD pattern obtained from separated, consolidated, and dried precipitate is reported in Figure 3. 


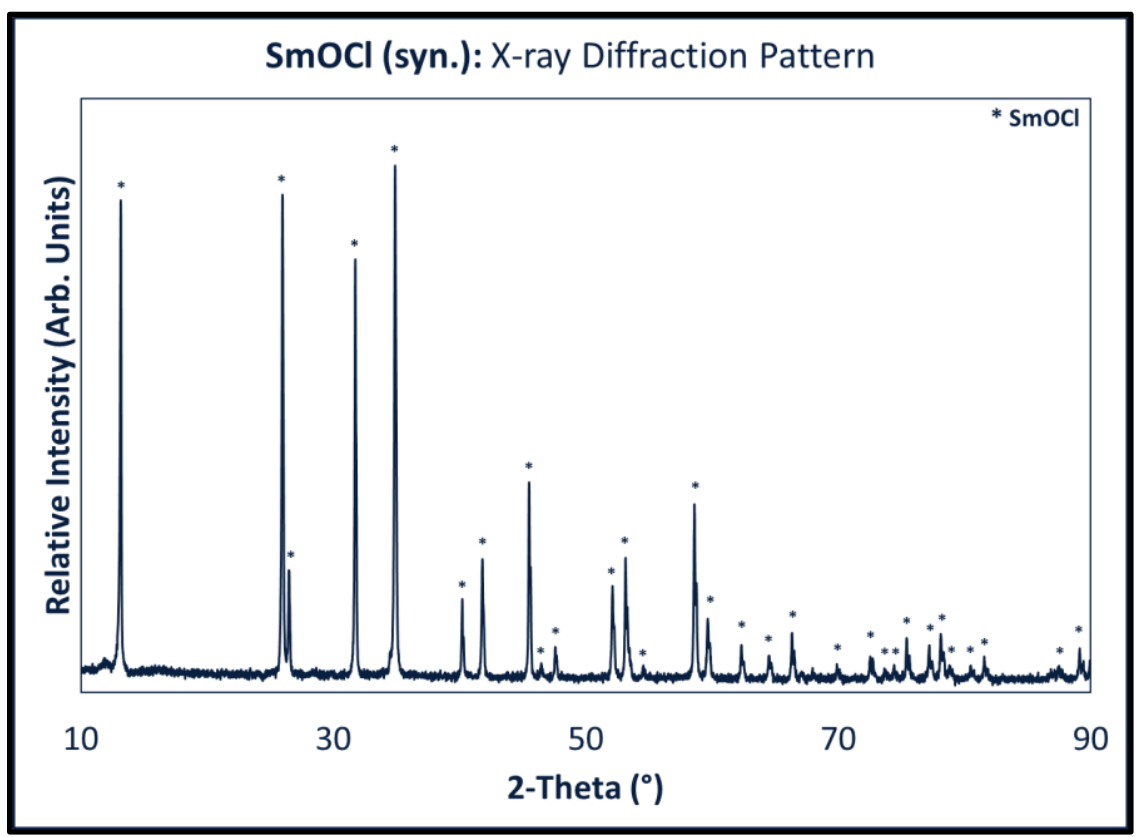

Figure 3: The XRD pattern obtained from separated, consolidated, and dried precipitate indicates the formation of SmOCI with relatively few impurities.

XRD analysis is followed by SEM imaging and EDS elemental analysis. Two different particulate morphologies can be observed in the SEM micrographs. EDS elemental analysis is conducted with respect to the $\mathrm{Sm}: \mathrm{Cl}$ atomic ratios. $\mathrm{SmOCl}$ should exhibit 1:1 Sm:Cl atomic ratios, while $\mathrm{SmCl}_{3}$ will exhibit 3:1 Sm:Cl ratios. The oxygen ratios are not reliable due to oxygen atmospheric and mounting tape contamination. The two different morphologies observed by SEM are displayed in Figure 4, and the regions of analysis by EDS are indicated. 


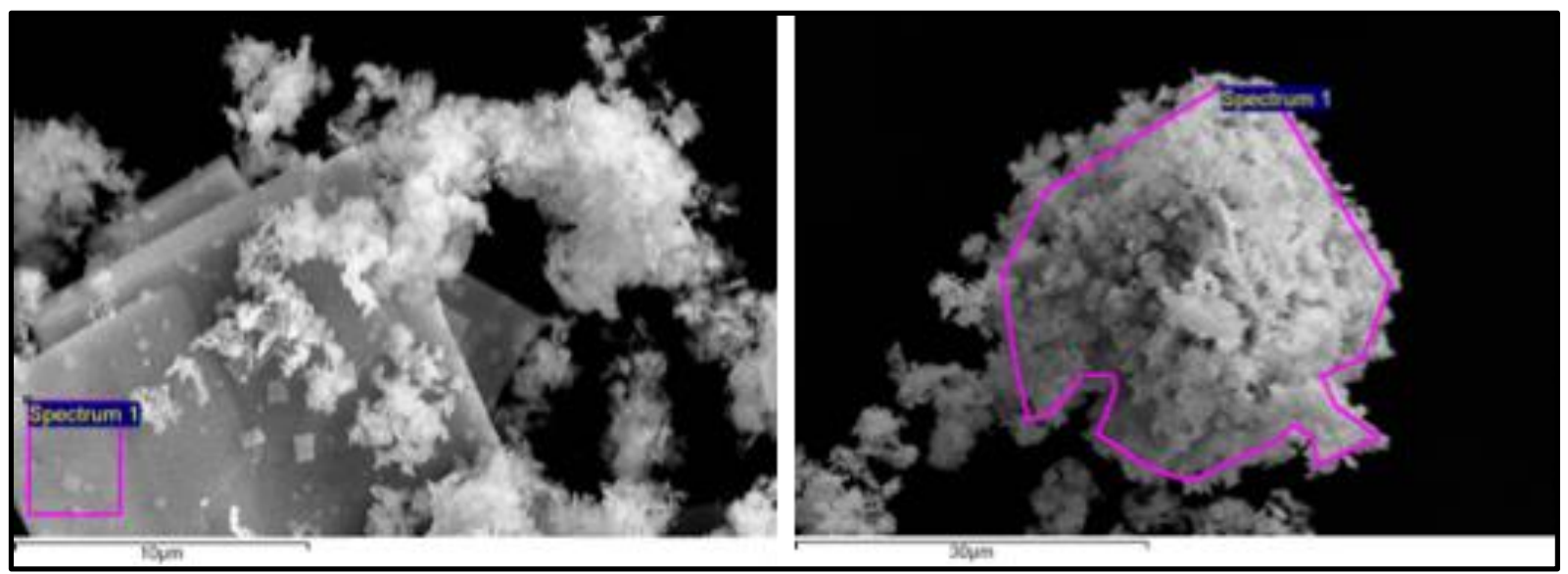

Figure 4: SEM images of plate-like precipitate particles (left) and fluff-like precipitate particles (right) both illustrate the regions of interest (purple outline) where EDS chemical analysis was conducted.

The EDS results are reported in Table 1 for both morphologies. The platinum content is attributed to the use of platinum to sputter coat samples before SEM-EDS analysis in order to prevent sample charging.

\begin{tabular}{|c|c|c|}
\hline & \multicolumn{2}{|c|}{ Atomic \% } \\
\hline Elemental Emission & Plate-Like Morphology & Fluff-Like Morphology \\
\hline O K & 58.61 & 52.44 \\
\hline CI K & 19.35 & 23.05 \\
\hline Sm L & 20.78 & 23.67 \\
\hline Pt M & 1.26 & 0.84 \\
\hline
\end{tabular}

Table 1: EDS chemical analysis results for both precipitate morphologies observed in SEM images indicated approximately 1:1 $\mathrm{Sm}: \mathrm{Cl}$ atomic ratio values.

Both morphologies indicate $\mathrm{Sm}: \mathrm{Cl}$ atomic ratios approximately $1: 1$, suggesting both morphologies are $\mathrm{SmOCl}$. These ratios confirm that the bulk precipitate collected is indeed SmOCl as the XRD pattern also suggests.

TEM imaging allows for planar, $d$-spacing to be measured. TEM imaging and $d$-spacing measurement results obtained from the precipitate are reported in Figure 5. 


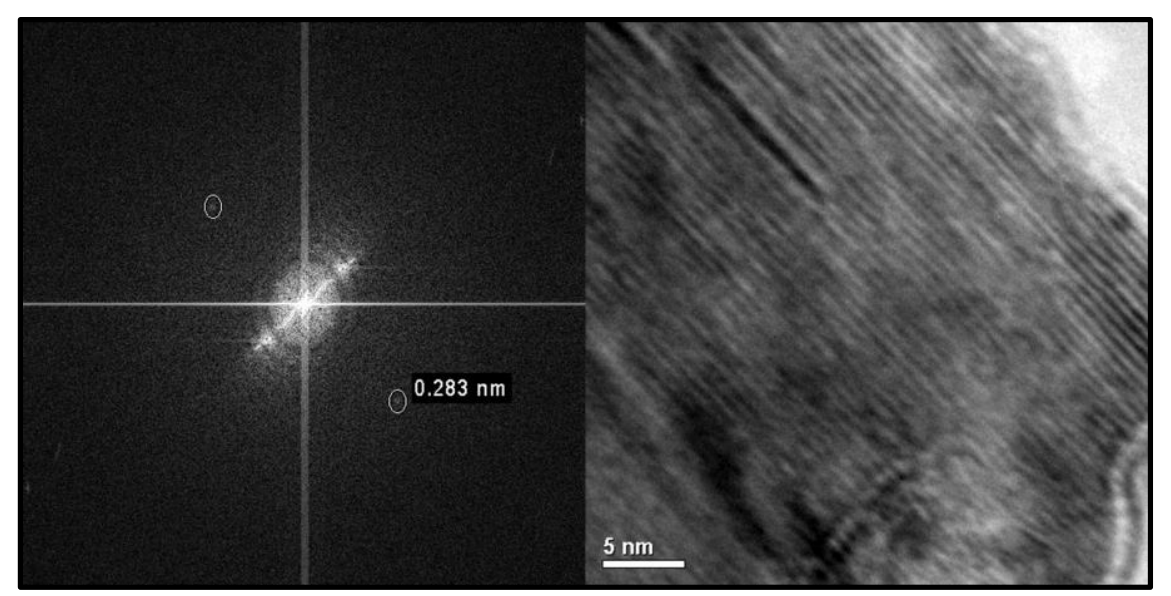

Figure 5: TEM diffraction analysis shows the 110-plane d-spacing is in agreement with the measured XRD pattern reported in Figure 3, confirming the precipitate to be SmOCl.

Once focusing on a plane of interest is achieved, a d-spacing measurement is confirmed with the 110plane associated with $\mathrm{SmOCl}$ and d-spacing values for the 110-plane measured using XRD. Solid-state Raman spectra obtained from the precipitate are reported in Figure 6.

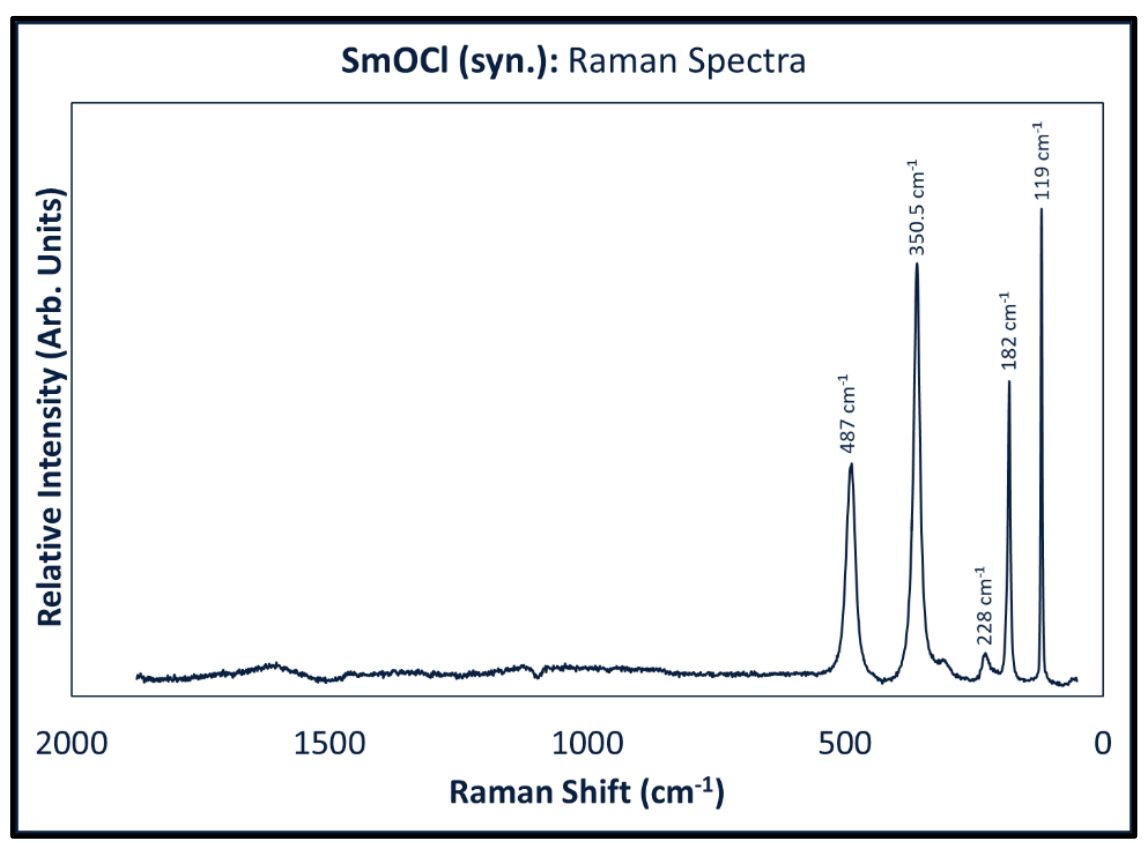

Figure 6: Raman spectra obtained from the precipitate show five symmetry modes that confirm the precipitate to be SmOCl. ${ }^{28}$

Raman spectra indicate the presence of five symmetrical modes labelled in Figure 6. These modes are confirmed to be consistent with the previously reported literature concerning lanthanide oxychlorides. ${ }^{28,}$ 
Solid-state characterization results all indicate the precipitate synthesized in the molten $\mathrm{LiCl}-\mathrm{KCl}$ $\mathrm{SmCl}_{3}$ solution is indeed $\mathrm{SmOCl}$, as Equations 2-4 suggest. The TEM images confirm the $\mathrm{d}$-spacing values reported for the 110-plane in the obtained XRD patterns, and the SEM-EDS results show the presence of two different morphologies, both of which can be attributed to $\mathrm{SmOCl}$ through $\mathrm{Sm}: \mathrm{Cl}$ atomic ratio analysis. The solid-state Raman spectra report five symmetrical modes that are consistent with the previously published lanthanide oxychloride literature. ${ }^{28,29}$

\section{In Situ Electrochemistry and Spectroscopy}

$\mathrm{CV}$ experiments conducted on $\mathrm{LiCl}-\mathrm{KCl}$ with $\mathrm{SmCl}_{3}$ solvated at low concentrations may produce an additional anodic peak in a slightly more oxidative region than that associated with the traditional $\mathrm{SmCl}_{3}$ redox couple. A sample CV that contains this additional anodic peak, indicated with an asterisk, is reported in Figure 7.

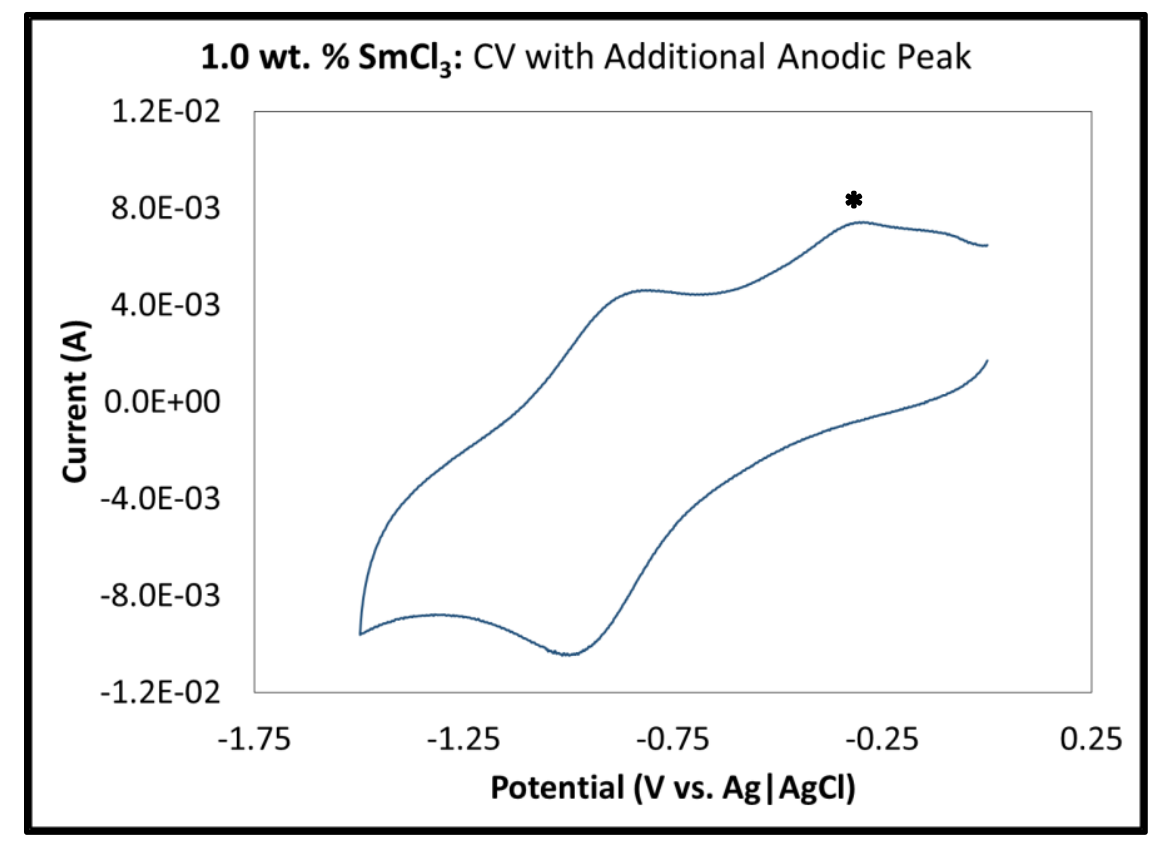

Figure 7: An additional anodic peak $\left({ }^{*}\right)$ manifests in a slightly more oxidative region than the traditional $\mathrm{SmCl}_{3}$ redox couple at low concentrations. 
The additional anodic peak is hypothesized to be the result of SmOCl formation. The CV reported in Figure 7 is compared with a CV obtained from the molten $\mathrm{LiCl}-\mathrm{KCl}$ eutectic solvated only with synthesized $\mathrm{SmOCl}$ in Figure 8.

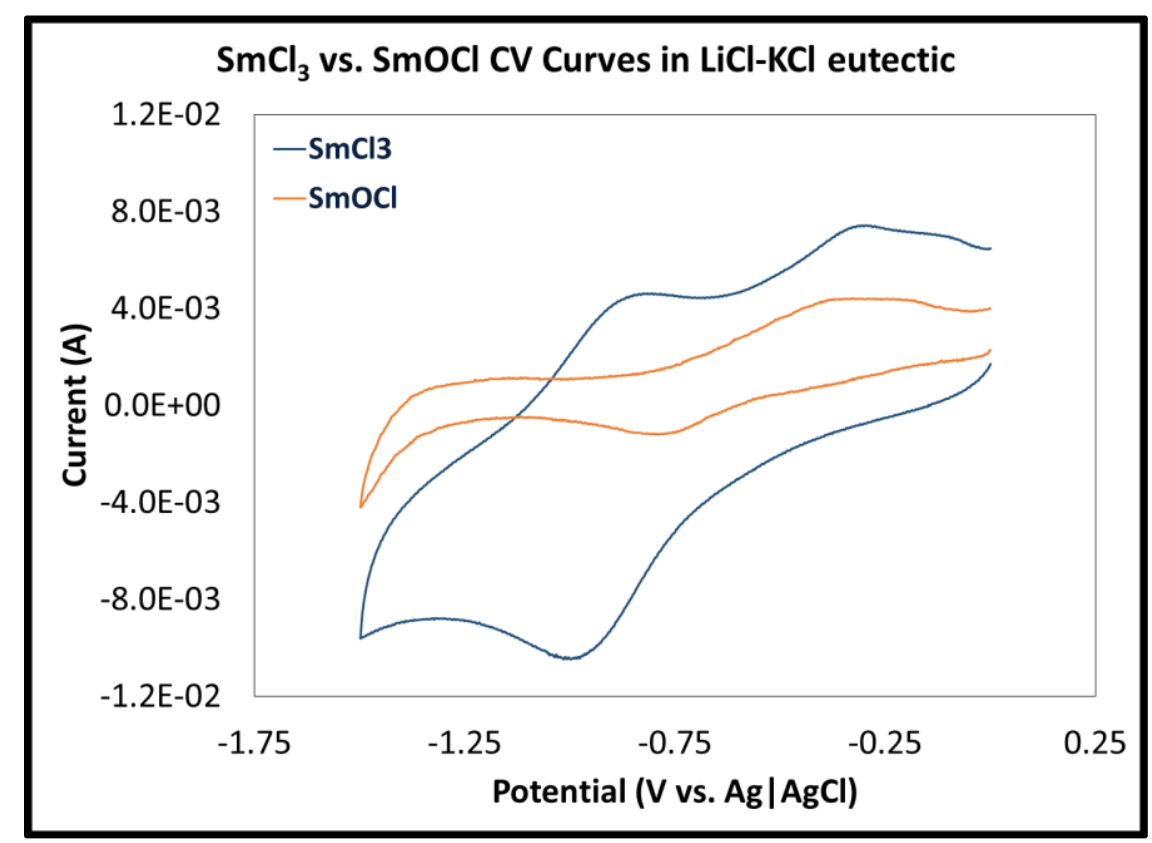

Figure 8: A comparison of CV curves obtained from a low-concentration $\mathrm{SmCl}_{3}$ melt with the additional anodic peak and a molten $\mathrm{LiCl}-\mathrm{KCl}$ melt containing synthesized SmOCl indicate the additional peak is due to SmOCl formation.

Figure 8 illustrates $\mathrm{SmOCl}$ is responsible for the additional anodic peak observed in molten $\mathrm{LiCl}-\mathrm{KCl}$ melts solvated with low concentrations of $\mathrm{SmCl}_{3}$. The $\mathrm{SmOCl}$ couple also includes a cathodic peak that manifests underneath the more prominent $\mathrm{SmCl}_{3}$ cathodic peak. The additional cathodic and anodic redox peaks that are the result of $\mathrm{SmOCl}$ contamination will create uncertainty in $\mathrm{SmCl}_{3}$ current response measurements which will have nuclear material management implications in terms of monitoring $\mathrm{SmCl}_{3}$ content.

In order to better understand the electroanalytical implications of $\mathrm{SmOCl}$ formation, the oxychloride was synthesized using the methods outlined in previous sections of this paper and then studied using CV and fiber-based Raman spectroscopy. CV and Raman analysis were first conducted on a molten $\mathrm{LiCl}-\mathrm{KCl}$ melt solvated with $\mathrm{SmCl}_{3}$ at a concentration of $3.3 \times 10^{-4} \mathrm{~mol} \mathrm{~cm}^{-3}$. The equimolar synthesis of $\mathrm{SmOCl}$ was then conducted through $\mathrm{Li}_{2} \mathrm{CO}_{3}$ solvation to convert the $\mathrm{SmCl}_{3}$ to $\mathrm{SmOCl}$. $\mathrm{CV}$ and in situ 
Raman were conducted to confirm the $\mathrm{SmCl}_{3}$ is no longer present after synthesis is compltete. A more targeted $\mathrm{CV}$ analysis was then conducted on the $\mathrm{SmOCl}$ in the $\mathrm{LiCl}-\mathrm{KCl}$ melt. Figure 9 and 10 respectively report in situ CV results and Raman spectra of $\mathrm{SmCl}_{3}$ solvated in the molten $\mathrm{LiCl}-\mathrm{KCl}$ eutectic that is consistent with the reported literature, and the subsequent disappearance of $\mathrm{SmCl}_{3}$ Raman indicators post-synthesis of the SmOCl. ${ }^{9,19}$

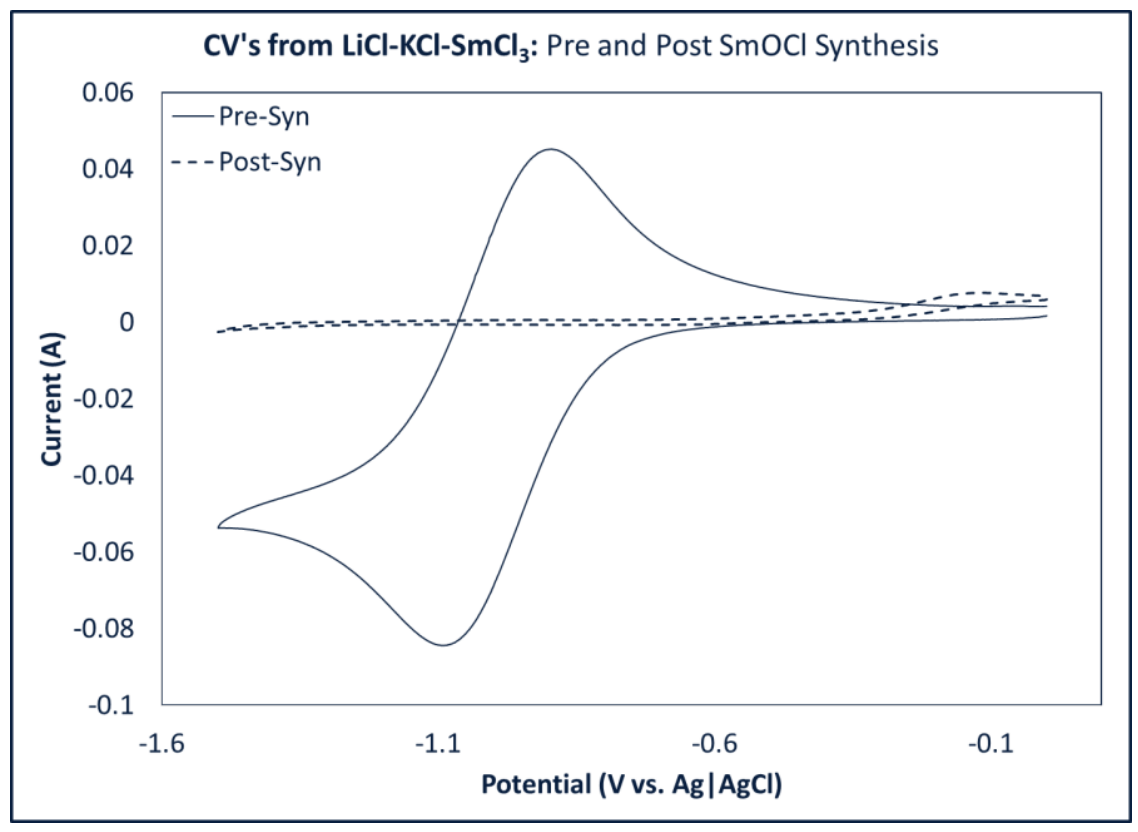

Figure 9: A clear shift in the location and magnitude of the peak current response is observed in the CV acquired post-SmOCI synthesis as compared to the CV acquired before $\mathrm{SmOCl}$ synthesis. 


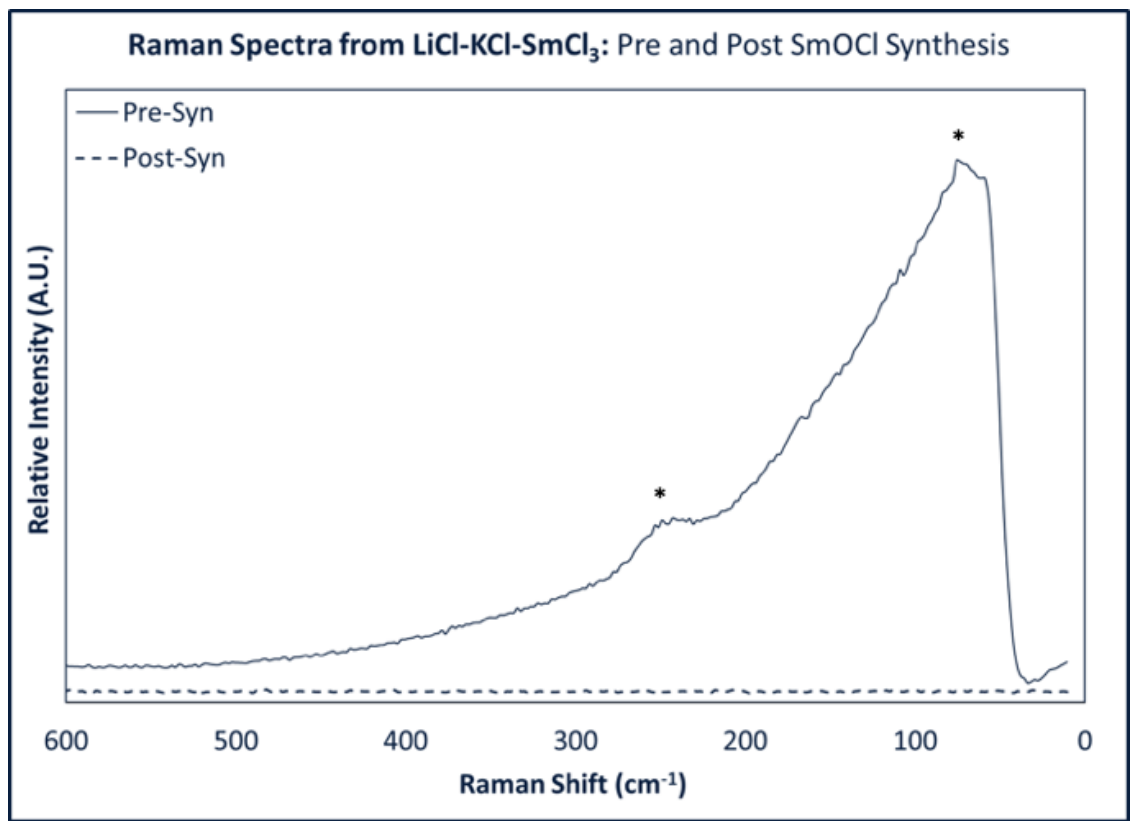

Figure 10: The lack of features in the Raman spectra acquired after the SmOCl synthesis indicate the SmOCl is either soluble at levels below the detection limits of the Raman or does not exhibit Raman active modes when solvated in the molten LiCl-KCl eutectic.

The peak current response from $\mathrm{SmOCl}$ is less in terms of magnitude than the solvated $\mathrm{SmCl}_{3}$. Figure 9 illustrates this shift in magnitude as the post-synthesis, $\mathrm{SmOCl}$ redox peaks are barely visible compared to the prominent, pre-synthesis $\mathrm{SmCl}_{3}$ peaks. This reduction in magnitude, along with the observable collection of $\mathrm{SmOCl}$ precipitate at the bottom of the melts suggests $\mathrm{SmOCl}$ is soluble at low levels in the molten LiCl-KCl eutectic. This low solubility may explain why no Raman indicators are detected postsynthesis in Figure 10; however, this lack of modes may also be attributed to dissolved $\mathrm{SmOCl}$ not being Raman active. There is no available literature regarding the coordination chemistry of $\mathrm{SmOCl}$ solvated in the molten $\mathrm{LiCl}-\mathrm{KCl}$ eutectic so that its Raman activity can be determined. Investigations of fundamental coordination chemistry requires techniques such as $x$-ray absorption fine structure (XAFS) analysis.

The peak current responses from $\mathrm{CV}$ associated with $\mathrm{SmCl}_{3}$ reached values above $100 \mathrm{~mA}$, while the same peak current responses all remained below $10 \mathrm{~mA}$ for $\mathrm{SmOCl}$. This difference in magnitude further suggests the low solubility of $\mathrm{SmOCl}$ in the molten $\mathrm{LiCl}-\mathrm{KCl}$ eutectic. The results of $\mathrm{CV}$ analysis as a 
function of scan rate are summarized for the $\mathrm{LiCl}-\mathrm{KCl}-\mathrm{SmCl}_{3}$ (pre-synthesis) and $\mathrm{LiCl}-\mathrm{KCl}-\mathrm{SmOCl}$ (postsynthesis) melts in Figures 11 and 12 respectively.
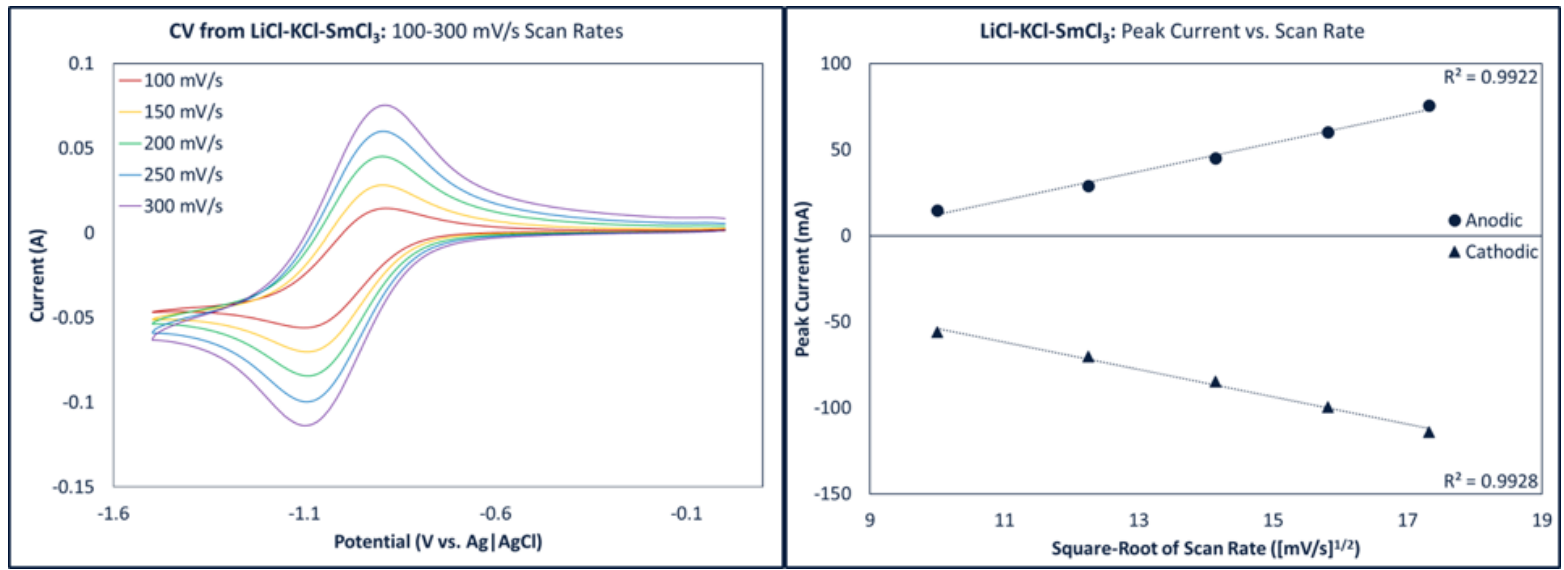

Figure 11: CV results (left) with respect to scan rate from the $\mathrm{LiCl}-\mathrm{KCl}-\mathrm{SmCl}_{3}$ (pre-synthesis) indicate high levels of peak current vs. scan rate linearity (right), and therefore high levels of Randles-Sevcik applicability.
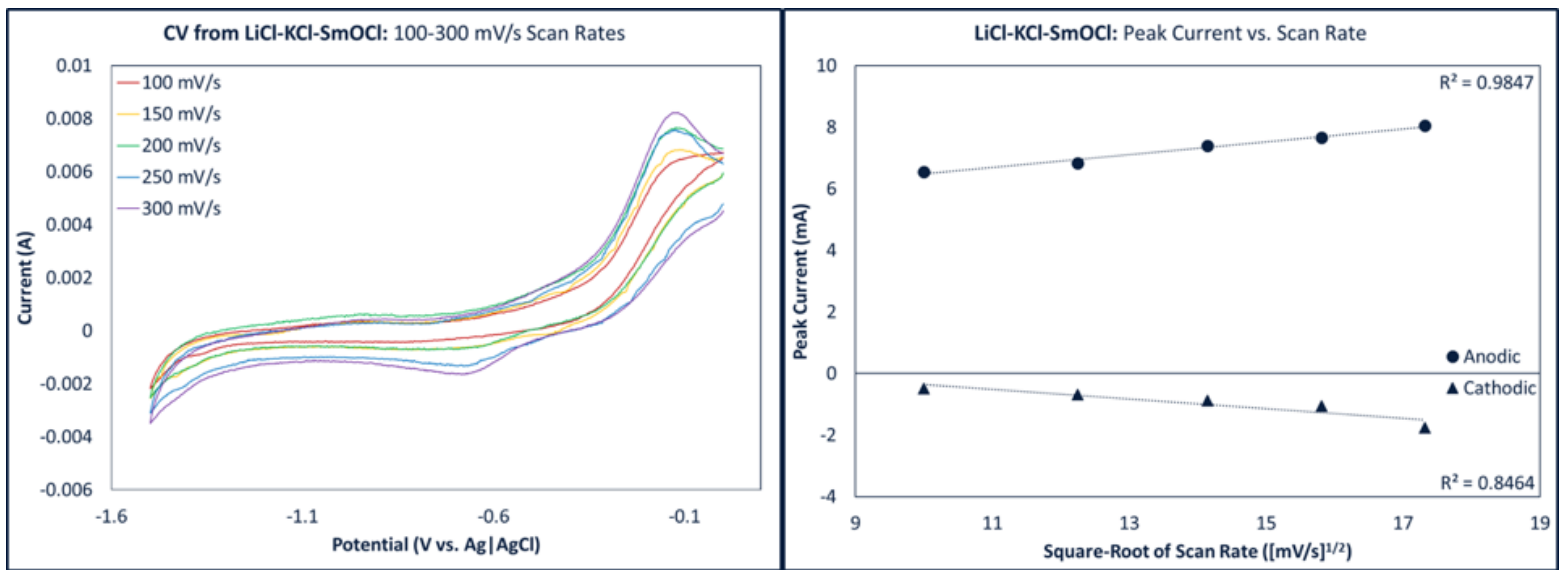

Figure 12: CV results (left) with respect to scan rate from the LiCl-KCl-SmOCl (post-synthesis) indicate lower levels of peak current vs. scan rate linearity (right), and therefore lower levels of Randles-Sevcik applicability.

The linearity of peak current vs. scan rate relationships, both for cathodic and anodic current response, is much higher for $\mathrm{SmCl}_{3}$ (pre-synthesis) samples than $\mathrm{SmOCl}$ (post-synthesis) samples. This difference in linearity is illustrated by the difference in $R^{2}$ values reported in Figures 11 and 12 . Randles-Sevcik applicability for analysis is therefore less suitable for the oxychloride species than $\mathrm{SmCl}_{3}$. The dissolution behavior in terms of ionic state equilibrium also seems to vary between the $\mathrm{SmCl}_{3}$ and $\mathrm{SmOCl}_{3} \mathrm{samples}$ Specifically, the $\mathrm{SmCl}_{3}$ samples produce cathodic peak current responses slightly larger than the anodic responses, suggesting the trivalent samarium that is reduced on the cathodic sweep is not fully oxidized 
back into solution. In comparison, the anodic current responses are much larger than the cathodic responses for the $\mathrm{SmOCl}$ samples. The literature is limited regarding the nature of oxychloride redox reactions, but this difference in current response relationships suggests the $\mathrm{SmOCl}$ could be more likely to undergo spontaneous reduction. Therefore, there is less oxidized species to reduce on the cathodic sweep, producing lower cathodic response. XAFS analysis may help elucidate these equilibrium conditions as well.

The implications of these findings regarding the application of CV for process monitoring and nuclear material management are notable. Carbonate or moisture impurities have the potential to convert solvated trichloride analytes to their oxychloride forms. Correcting for SmOCl is clearly necessary as it is electroactive and produces distinguishable redox peaks in CV curves. Current correction methods must be developed for oxychloride species to account for their contributions to solvated trichloride analysis. Developing these correction methods will not be trivial, as the applicability of Randles-Sevcik relationship loses effectiveness when studying the oxychloride species. Elucidation of ionic states and equilibria associated with oxychloride species must first be investigated before any adjustments to the Randles-Sevick can be accomplished. These studies would most likely require fundamental coordination chemistry investigations using methods such as XAFS.

\section{Conclusions}

A targeted synthesis, solid-state characterization, in situ electroanalytical, and in situ Raman spectroscopic investigation of $\mathrm{SmOCl}$ in the molten $\mathrm{LiCl}-\mathrm{KCl}$ eutectic was completed. Synthesis was accomplished through carbonate addition to the molten $\mathrm{LiCl}-\mathrm{KCl}-\mathrm{SmCl}_{3}$ system. $\mathrm{SmOCl}$ was confirmed to precipitate out of solution due to carbonate addition through a variety of solid-state characterization techniques. The SmOCl was then analyzed in situ using fiber-based Raman spectroscopy and cyclic voltammetry. Both the Raman and voltammetry results indicated a conversion of $\mathrm{SmCl}_{3}$ to $\mathrm{SmOCl}$ and 
change in solution chemistry. The SmOCl was not detectable using Raman either due to its solubility limit being below the Raman's detection limits or its solvated form being Raman inactive. CV investigations into the $\mathrm{SmOCl}$ produced redox peaks that suggest current corrections will be necessary for $\mathrm{SmOCl}$ when using $\mathrm{CV}$ for process monitoring and nuclear material management purposes in the molten $\mathrm{LiCl}-\mathrm{KCl}$ eutectic.

\section{Conflicts of Interest}

There are no conflicts to declare.

\section{Acknowledgements}

This work was supported by the United States Department of Energy (DOE) under Contracts DE-NE0008236 and DE-NE0008572, and the United States Nuclear Regulatory Commission (NRC) under Contract NRC-HQ-13-G-38-0027. Dr. Kenny Osborne and Ms. Nancy Hebron-Israel serve as the DOE and NRC award program managers, respectively. VJS acknowledges the NRC fellowship award for financial support and Materials Characterization Nevada (MCNV) for assistance with solid-state characterization.

\section{References}

1. I. A. E. AGENCY, Climate Change and Nuclear Power 2018, INTERNATIONAL ATOMIC ENERGY AGENCY, Vienna, 2018.

2. S. Saito, Journal of Nuclear Materials, 2010, 398, 1-9.

3. K. L. Murty and I. Charit, Journal of Nuclear Materials, 2008, 383, 189-195. 
4. P. L. Lafreniere, D. S. Rappleye, R. O. Hoover, M. F. Simpson and E. D. Blandford, Nuclear Technology, 2015, 189, 173-185.

5. J. L. Willit, W. E. Miller and J. E. Battles, Journal of Nuclear Materials, 1992, 195, 229-249.

6. M. A. Williamson and J. L. Willit, Nuclear Engineering and Technology, 2011, 43, 329-334.

7. M. T. Cook, 2015.

8. C. Zhang, D. Rappleye and M. F. Simpson, ECS Transactions, 2016, 75, 95-103.

9. T. Uda, T. Fujii, Y. Iwadate, A. Uehara and H. Yamana, Zeitschrift für anorganische und allgemeine Chemie, 2013, 639, 765-769.

10. M. M. Tylka, J. L. Willit, J. Prakash and M. A. Williamson, Journal of The Electrochemical Society, 2015, 162, H625-H633.

11. S.-E. Bae, T. S. Jung, Y.-H. Cho, J.-Y. Kim, K. Kwak and T.-H. Park, Inorganic chemistry, 2018.

12. G. Cordoba and C. Caravaca, Journal of Electroanalytical Chemistry, 2004, 572, 145-151.

13. M. lizuka, T. Inoue, O. Shirai, T. Iwai and Y. Arai, Journal of Nuclear Materials, 2001, 297, 43-51.

14. T. J. Kim, Y. Jung, S. H. Kim, S. W. Paek and D. H. Ahn, BULLETIN OF THE KOREAN CHEMICAL SOCIETY, 2011, 32, 863-866.

15. A. Samin, Z. Wang, E. Lahti, M. Simpson and J. Zhang, Journal of Nuclear Materials, 2016, 475, $149-155$.

16. H. C. Eun, Y. Z. Cho, S. M. Son, T. K. Lee, H. C. Yang, I. T. Kim and H. S. Lee, Journal of Nuclear Materials, 2012, 420, 548-553.

17. H. C. Eun, J. H. Choi, N. Y. Kim, T. K. Lee, S. Y. Han, S. A. Jang, T. J. Kim, H. S. Park and D. H. Ahn, Journal of Nuclear Materials, 2017, 491, 149-153. 
18. S. J. Zygmunt, C. F. V. Mason and W. K. Hahn, 2000.

19. Y. Castrillejo, C. de la Fuente, M. Vega, F. de la Rosa, R. Pardo and E. Barrado, Electrochimica Acta, 2013, 97, 120-131.

20. V. Singh and D. Chidambaram, Salt Lake City, Utah, 2016.

21. V. Singh and D. Chidambaram, San Diego, California, 2017.

22. V. Singh and D. Chidambaram, Meeting Abstracts, 2017, MA2017-02, 765-765.

23. V. J. Singh, C. D. Bruneau and D. Chidambaram, 2019.

24. A. J. Bard, L. R. Faulkner, J. Leddy and C. G. Zoski, Electrochemical methods: fundamentals and applications, wiley New York, 1980.

25. M. M. Tylka, J. L. Willit, J. Prakash and M. A. Williamson, Journal of The Electrochemical Society, 2015, 162, H852-H859.

26. K. Sridharan, T. Allen, M. Anderson and M. Simpson, Thermal Properties of LiCl-KCl Molten Salt for Nuclear Waste Separation, USDOE (United States); Nuclear Energy University Programs (United States), United States of America, 2012.

27. J.-F. Vigier, A. Laplace, C. Renard, M. Miguirditchian and F. Abraham, Journal of Nuclear Materials, 2018, 499, 394-400.

28. H. Haeuseler, Spectrochimica Acta Part A: Molecular Spectroscopy, 1982, 38, 505-507.

29. G. D. Del Cul, S. E. Nave, G. M. Begun and J. R. Peterson, Journal of Raman spectroscopy, 1992, 23, 267-272. 